University of Nebraska - Lincoln

DigitalCommons@University of Nebraska - Lincoln

Faculty Publications -- Chemistry Department Published Research - Department of Chemistry

2008

\title{
Classification of Chemical Reactions: Stages of Expertise
}

\author{
Marilyne Stains \\ University of Nebraska-Lincoln, mstains2@unl.edu \\ Vicente Talanquer \\ University of Arizona, vicente@u.arizona.edu
}

Follow this and additional works at: https://digitalcommons.unl.edu/chemfacpub

Part of the Chemistry Commons

Stains, Marilyne and Talanquer, Vicente, "Classification of Chemical Reactions: Stages of Expertise" (2008). Faculty Publications -- Chemistry Department. 49.

https://digitalcommons.unl.edu/chemfacpub/49

This Article is brought to you for free and open access by the Published Research - Department of Chemistry at DigitalCommons@University of Nebraska - Lincoln. It has been accepted for inclusion in Faculty Publications -Chemistry Department by an authorized administrator of DigitalCommons@University of Nebraska - Lincoln. 
Published in the Journal of Research in Science Teaching 45:7 (2008), pp. 771-793; doi: 10.1002/ tea.20221.

Copyright (C) 2007 Wiley Periodicals, Inc. Used by permission.

Submitted August 21, 2006; accepted May 1, 2007, published online August 6, 2007.

\title{
Classification of Chemical Reactions: Stages of Expertise
}

\author{
Marilyne Stains and Vicente Talanquer \\ Department of Chemistry, University of Arizona, Tucson, Arizona \\ Corresponding author - V. Talanquer, vicente@u.arizona.edu
}

\begin{abstract}
In this study we explore the strategies that undergraduate and graduate chemistry students use when engaged in classification tasks involving symbolic and microscopic (particulate) representations of different chemical reactions. We were specifically interested in characterizing the basic features to which students pay attention when classifying chemical reactions at the symbolic and microscopic levels. We identified the categories that students create when classifying chemical reactions, and compared the performance in simple classification tasks of students with different levels of preparation in the discipline. Our results suggest that advanced levels of expertise in chemical classification do not necessarily evolve in a linear and continuous way with academic training; a significant proportion of undergraduate students, regardless of their level of preparation in chemistry, based their classification schemes on the identification of surface features and failed to create chemically meaningful classes. Students' ability to identify chemically meaningful groups was strongly influenced by their recent learning experiences and their graduate work in chemistry. The level of expertise and the type of chemical representation influenced the number and types of categories created, the nature of the features used to build a class, and the role that these features played during the classification process. Although all of the participants in our study expressed similar levels of unfamiliarity with the microscopic images of chemical reactions, advanced students were more adept at using the available representational features to build chemical meaning.
\end{abstract}

Keywords: chemistry, cognitive development, problem-solving

Classification plays a central role in science, where it is used not only as a way to organize knowledge but also as a powerful predictive tool. In particular, chemists rely heavily on classification systems in their everyday work, from selecting a solvent to carry out a reaction to identifying a molecule based on a set of spectra (Schummer, 1998). Unfortunately, very little is known about students' ability to use and apply these classification schemes. Students' alternative conceptions about different types of substances (del Pozo, 2001; Nakhleh \& Samarapungavan, 1999; Papageorgiou \& Sakka, 2000; Sanger, 2000), types of processes (Abraham, Williamson, \& Westbrook, 1994), or types of bonding (Barker \& Millar, 2000; Birk \& Kurtz, 1999; Coll \& Treagust, 2001) have been thoroughly investigated. However, very little attention has been given to exploring the strategies used by chemistry learners with different levels of expertise when classifying substances, processes, or interactions into different groups.

The diverse classification systems used in chemistry to make predictions and build explanations are based on the identification of features at different levels of representation: macroscopic, microscopic, and symbolic (Gabel, 1999; Johnstone, 1993). Research has shown that students have difficulties in translating their understanding from one level to another (Al-Kunifed, Good, \& Wandersee, 1993; Benzvi, Eylon, \& Silberstein, 1986; Gabel, 1999; Wu \& Shah, 2004). In particular, work by Kozma and Russell (1997), on novice and expert responses to different representations of chemical phenomena, suggests that the classification systems built by novices may be strongly influenced by the types of representations used in a given problem.

Research on expertise indicates that the understanding of novices is both enabled and constrained by the surface features of the types of representations in a problem (Chi, Feltovich, \& Glaser, 1981; Larkin, 1983). Although experts recognize the same surface features, they can use their prior 
knowledge to build meaningful understandings regardless of the form of representation. The highly interconnected knowledge structure of experts allows them to recognize patterns and principles that novices cannot detect (Glaser, 1989). Our previous investigation of the patterns of reasoning used by novice chemistry students to classify chemical substances based on their particulate representations supports these conclusions (Stains \& Talanquer, 2007). In that study, strong associations between concepts (e.g. atom-element, compound-molecule) led novice students to reduce the number of relevant features used to differentiate between substances, whereas the inability to discriminate between two concepts (e.g. compound-mixture) led them to pay too much attention to irrelevant features during the classification tasks.

In this study we extend our work on the acquisition of expertise in chemical classification to examine the knowledge structure and thinking processes of chemistry students when engaged in classification tasks involving symbolic and microscopic (particulate) representations of different chemical reactions. In particular, we studied the classification strategies of undergraduate and graduate chemistry students using think-aloud interviews in which participants were asked to classify 15 different chemical reactions. We were specifically interested in: (a) characterizing the basic features to which students pay attention when classifying chemical reactions at the symbolic and microscopic levels; (b) identifying the categories that students create when classifying chemical reactions; and (c) comparing the performance in simple classification tasks of students with different levels of preparation in the discipline. This type of study is of fundamental importance to better understand how expertise develops in academic domains and to characterize how knowledge representations evolve with training.

\section{Theoretical Framework}

Classification can be defined as the basic cognitive task of arranging concepts into classes or categories. It is a cognitive process that allows us to reduce both the complexity of the environment and the need for constant learning through the organization of knowledge into classes of related objects and events (Bruner, 1956). Psychological theories of classification traditionally follow one of these three approaches: ruled-based (classical view); similarity-based; or theory-based. There is considerable debate concerning the strengths and limitations of each of these views (Murphy, 2002). In a rule-based theory of categorization, a classification is made by identifying a set of necessary and sufficient features. This approach to categorization is common in areas such as science, where many concepts have strict definitions. However, researchers have argued that many important concepts cannot be clearly defined and that, in these cases, categorization is based on perceptual similarity (Margolis \& Laurence, 1999). In a similarity-based view of categorization, classifications are made based on perceived similarities between a stimuli and mnemonic stores of a prototype or exemplars of a given category. Recent results by Rouder and Ratcliff (2006) suggest that the use of rules (classic view) or exemplars (similarity view) in categorization may depend on the level of expertise. Novice learners may find perceived features confusing and rely heavily on rules when completing a classification task. During learning, stimuli can be stored as exemplars and then used to categorize novel stimuli based on similarity rather than formal rules.

Cognitive psychologists who hold a theory-based or knowledge approach to concept construction and categorization argue that we do not learn concepts in isolation but as part of our overall understanding of the surrounding world. They maintain that prior knowledge and contextual factors strongly influence the nature and interpretation of the features that individuals select to define a class (Barsalou, 1983; Hayes, Foster, \& Gadd, 2003; Margolis \& Laurence, 1999; Murphy \& Medin, 1985), and affect the way in which perceptual features are transformed into meaningful patterns (Palmeri \& Blalock, 2000). People seem to classify concepts in terms of hidden properties and essential features that reflect their general knowledge and personal beliefs (Medin, Lynch, Coley, \& Atran, 1997; Murphy \& Medin, 1985).

The development of expertise in a given area affects the ways in which individuals organize their knowledge in the domain and how they use this knowledge to understand the world around them (Glaser, 1989). Thus, from the theory-based perspective one should also expect differences in expert-novice classification patterns. Research in this area indicates that novices develop classification schemes based on surface features, whereas experts consider both surface features and underlying concepts (Day \& Lord, 1992; Johnson, 2001; Tanaka \& Taylor, 1991). Related studies have shown that experts build fewer but more integrated classes during free classification 
tasks (Kozma \& Russell, 1997), and make finer distinctions between groups (Rosch, Mervis, Gray, Johnson, \& Boyesbraem, 1976).

Studies of expert-novice differences in classification patterns in science have focused mostly on understanding people'sclassification of concepts belonging to the natural world. For example, there are several studies on the effect of expertise in the classification of natural kinds, such as birds (Bailenson, Shum, Atran, Medin, \& Coley, 2002; Johnson, 2001; Tanaka \& Taylor, 1991) and trees (Medin et al., 1997). Other investigators have compared novice and expert approaches to the classification of physics and chemistry problems (Chi et al., 1981; Finney \& Schwenz, 2005), and to the categorization of different representations of chemical phenomena (Kozma \& Russell, 1997).However, analysis of the effect of expertise on the classification of scientific theoretical constructs has been largely overlooked, particularly in the field of chemistry (Thagard \& Toombs, 2005).

Most research studies on expertise have analyzed expert-novice differences rather than expertise acquisition (Lajoie, 2003). Although we certainly have a good understanding of how expertise develops in skill-based professions, such as medicine, nursing, and music (Ericsson, 2003; Hmelo, 1998), much less is known about the acquisition of expertise in the scientific domains. The characterization of common trajectories toward expertise in these areas could be useful in the design of instruction and assessments that more effectively develop competence at different stages. For example, a recent study on the early stages of expertise acquisition involving freshmen and senior engineering students (Moss, Kotovsky, \& Cagan, 2006) highlighted fundamental changes in the way novice and more advanced students recall and represent mechanical devices. Based on their results, the authors suggested that engineering students may benefit from instruction that makes concrete the functional properties of groups of components rather than individual pieces in a given device.

Our research work over the past few years has been focused on better characterizing the stages or trajectories of expertise associated with the classification of chemical substances, processes, and interactions. In particular, the central goal of this study was to investigate the classification strategies used by undergraduate and graduate chemistry students when engaged in classification tasks involving symbolic and microscopic (particulate) representations of different chemical reactions. For this purpose, individual participants were asked to classify 15 chemical reactions while simultaneously verbalizing their thought processes.

\section{Methods}

\section{Goals and Research Questions}

Our investigation was guided by the following research questions:

- What are the basic features to which students pay attention when classifying chemical reactions at the symbolic and microscopic levels?

- What are the categories that students create when classifying chemical reactions at the symbolic and microscopic levels?

- How do decisions about categorization of chemical reactions at the symbolic and microscopic levels vary among students with different levels of preparation in chemistry?

\section{Context and Participants}

This study was conducted at a public research I institution in the southwestern United States. The Chemistry Department at this university offers a variety of chemistry courses to over 2500 students each semester. The chemistry courses at the undergraduate level vary from basic fundamental chemistry courses, such as general chemistry and organic chemistry, to more advanced undergraduate chemistry courses, such as physical chemistry and analytical chemistry. The Chemistry Department also offers an array of graduate level courses for graduate students enrolled in the master's and doctoral programs in chemistry.

Volunteer participants were drawn from five different groups representing different levels of preparation in chemistry, as summarized in Table 1 . Most of the study was conducted toward the end of the fall academic semester; therefore, all of the freshman undergraduate students (GCI and GCII) had already been exposed to the topic of chemical reactions during the regular lecture. For ref- 
Table 1. Description of participants and levels of preparation

\begin{tabular}{llr}
\hline Group & Level & $n$ \\
\hline General Chemistry I (GCI) & First semester of general chemistry & 8 \\
General Chemistry II (GCII) & Second semester of general chemistry & 5 \\
Organic Chemistry I (OC) & First semester of organic chemistry & 6 \\
Senior-level chemistry (SS) & Enrolled in advanced courses & 12 \\
Graduate chemistry students (GS) & First to fifth year in a Chemistry PhD program & 13 \\
\hline
\end{tabular}

erence and privacy purposes, a code was created to label each of the participants; this code has been used throughout the discussion of our results. The assigned label is based on the students' level of preparation in chemistry and the order of the interview. For example, interviewee OCI1 refers to the first (1) student in the first semester of organic chemistry (OCI) who completed the interview.

\section{Instruments}

The data were collected through 1-hour, semistructured, think-aloud interviews conducted with each of the participants listed in Table 1 . This method was preferred because it helped to capture students' verbalized ideas and thoughts as they engaged in the activity. Each interview consisted of two tasks: classification of chemical reactions represented at the symbolic level, and classification of chemical reactions represented at the microscopic level. The chemical reactions selected for these tasks represented types of chemical reactions traditionally identified by chemists, such as acid-base reactions, oxidation-reduction reactions (redox reactions), and precipitation reactions. All interviews were tape-recorded and transcribed. In the following paragraphs we present a detailed description of each classification task.

Classification at the symbolic level. This classification was conducted at the beginning of the regular interviews. In this free classification task, students were asked to classify a total of nine chemical reactions represented at the symbolic level (Table 2), creating their own groups and labels. The reactions selected corresponded to typical textbook-type chemical reactions (e.g., Reaction b or e), reactions that have been found to mislead students' interpretation (e.g., students often believe that Reaction $h$ is a redox reaction because a charged molecule becomes neutral), and reactions that contained similar surface features (e.g., Reactions b, c, and h produce water). From a chemical standpoint, these

Table 2. Sets of symbolic representations of chemical reactions used during the first part of the interview and their correct classification from a chemistry standpoint

\begin{tabular}{|c|c|c|c|c|}
\hline & & $\begin{array}{l}\text { Reactions Provided } \\
\text { to the Participants }\end{array}$ & $\begin{array}{l}\text { Classification A } \\
\text { (Chemical Behavior) }\end{array}$ & $\begin{array}{l}\text { Classification B (Particle } \\
\text { Rearrangement) }\end{array}$ \\
\hline \multirow[t]{3}{*}{ Set 1} & a & $\begin{array}{l}\mathrm{NH}_{3}(\mathrm{~g})+\mathrm{H}_{2} \mathrm{O}(\mathrm{I}) \rightarrow \\
\quad \mathrm{NH}_{4}^{+}(\mathrm{aq})+\mathrm{OH}^{-}(\mathrm{aq})\end{array}$ & Acid-base & Addition \\
\hline & $\mathrm{b}$ & $\begin{array}{l}\mathrm{HF}(\mathrm{aq})+\mathrm{KOH}(\mathrm{aq}) \rightarrow \\
\quad \mathrm{KF}(\mathrm{aq})+\mathrm{H}_{2} \mathrm{O}(\mathrm{I})\end{array}$ & Acid-base & Double displacement \\
\hline & c & $\begin{array}{l}\mathrm{H}_{2}(\mathrm{~g})+\mathrm{CuO}(\mathrm{s}) \rightarrow \\
\quad \mathrm{H}_{2} \mathrm{O}(\mathrm{g})+\mathrm{Cu}(\mathrm{s})\end{array}$ & Redox & Single displacement \\
\hline \multirow[t]{3}{*}{ Set 2} & d & $\begin{array}{l}2 \mathrm{Na}(\mathrm{s})+2 \mathrm{HCl}(\mathrm{aq}) \rightarrow \\
\quad 2 \mathrm{NaCl}(\mathrm{aq})+\mathrm{H}_{2}(\mathrm{~g})\end{array}$ & Redox & Single displacement \\
\hline & e & $\begin{array}{l}\mathrm{NaCl}(\mathrm{aq})+\mathrm{AgNO}_{3}(\mathrm{aq}) \rightarrow \\
\quad \mathrm{AgCl}(\mathrm{s})+\mathrm{NaNO}_{3}(\mathrm{aq})\end{array}$ & Precipitation & Double displacement \\
\hline & $\mathrm{f}$ & $\begin{array}{l}2 \mathrm{NaOH}(\mathrm{aq})+\mathrm{FeCl}_{2}(\mathrm{aq}) \rightarrow \\
\quad \mathrm{Fe}(\mathrm{OH})_{2}(\mathrm{~s})+2 \mathrm{NaCl}(\mathrm{aq})\end{array}$ & Precipitation & Double displacement \\
\hline \multirow[t]{3}{*}{ Set 3} & $\mathrm{~g}$ & $\begin{array}{l}\mathrm{Fe}(\mathrm{s})+2 \mathrm{CuCl}(\mathrm{aq}) \rightarrow \\
\quad \mathrm{FeCl}_{2}(\mathrm{aq})+2 \mathrm{Cu}(\mathrm{s})\end{array}$ & Redox & Single displacement \\
\hline & $\mathrm{h}$ & $\begin{array}{c}\mathrm{CO}_{3}{ }^{2-}(\mathrm{aq})+2 \mathrm{H}^{+}(\mathrm{aq}) \rightarrow \\
\mathrm{H}_{2} \mathrm{O}(\mathrm{I})+\mathrm{CO}_{2}(\mathrm{~g})\end{array}$ & Acid-base & Double displacement \\
\hline & i & $\mathrm{Pb}^{2}+(\mathrm{aq})+2 \mathrm{I}^{-}(\mathrm{aq}) \rightarrow \mathrm{PbI}_{2}(\mathrm{~s})$ & Precipitation & Double displacement \\
\hline
\end{tabular}


reactions could be classified either as: (a) Classification A (based on chemical behavior): acid-base, redox, or precipitation reactions; or (b) Classification B (based on particle rearrangement): addition or combination (two substances react to form a single product), single-displacement (one element reacts with a compound to form a new compound and release a different element), or double-displacement or exchange (there is an interchange of partners between two compounds) reactions. Classification A can be expected to be more meaningful for an expert chemist.

To reduce the demand on the students' working memory during the task, the reactions were divided into three sets of three chemical reactions, which were given to students one at a time (Table 2). The interview began with this instruction: "Classify the following reactions represented in symbolic form based on the similarities that you observe or detect; you may create as many groups as you want. Please label each of your groups and let us know what you are thinking at every stage of the task." Then, the participants were asked to independently classify two out of the three sets of chemical reactions based on similarities and differences that they perceived as important. In the next step, they were given the possibility of rearranging or combining the different categories created with each set. Finally, students classified the third set of chemical reactions using the categories that they had previously developed. They were also given the possibility of rearranging their groups and/or creating new ones.

Classification at the microscopic level. This classification task was completed following the classification at the symbolic level. This task consisted of classifying six chemical reactions represented at the microscopic level. Three of the six reactions were microscopic representations of reactions already introduced in the previous task (Reactions a, d, and g); the other three cases represented new examples of acid-base, redox, and precipitation reactions. The particulate representations are shown in the first column in Table 3, in which we include additional information to facilitate the reader's interpretation (the symbolic representations were not provided to the students in this stage). To reduce the cognitive demand on the participants, the reactions were provided one at a time and students were asked to classify each of them using the categories that they had developed in the previous task. However, they were allowed to rearrange the content of the categories, change their names, or create new ones during this process.

\section{Data Analysis}

Each interview transcript was carefully read, annotated, and summarized. The summary reported evidence from each classification task that was relevant to each of the research questions. Summaries were analyzed using grounded theory (Charmaz, 2003). In this iterative, nonlinear analysis, categories were generated by highlighting common statements and major ideas relevant to the research questions. Our analysis focused on the types of features to which students paid attention during the classification process (types of substances involved, presence of charged particles, etc.). Each classification task revealed a set of features, which were then regrouped according to common themes. These themes were used to recode the summaries and the new themes that emerged were integrated in the analysis. This strategy was repeated until a complete and coherent set of common themes was obtained. This set of themes was then applied to reanalyze each of the interview transcripts using the same strategy for the analysis. Several cycles of coding were necessary to obtain a satisfactory final set of themes. This process allowed us to identify the central features that students used to build their classification schemes as well as to discern how these features varied based on level of expertise.

To assess the reliability of our coding system, a total of 12 of 44 interviews (27\%) were simultaneously coded by the second author of this study. We started this process by coding four interview transcripts independently, comparing their analysis, and merging and readjusting coding categories as needed. In a second step, we separately applied the common code to a new set of four transcripts and repeated the comparison process. Finally, we recoded all of the selected transcripts plus a new group of four interview transcripts, and the results were used to calculate the interrater reliability. This analysis indicated $91 \%$ agreement in the coding of the types of features used by the participants and $86 \%$ agreement in the determination of how each feature was used during the classification task. The final coding scheme developed through this iterative process is presented in Table 4, together with some interview excerpts that illustrate its application. Our analysis revealed that students paid attention to both the visible elements of the representations of a chemical reaction (explicit features) as well as the underlying characteristics of the substances involved (implicit features). The students also used these features with different purposes, mainly to differentiate be- 
Table 3. Set of chemical reactions represented at the microscopic level and their correct classification from a chemistry standpoint

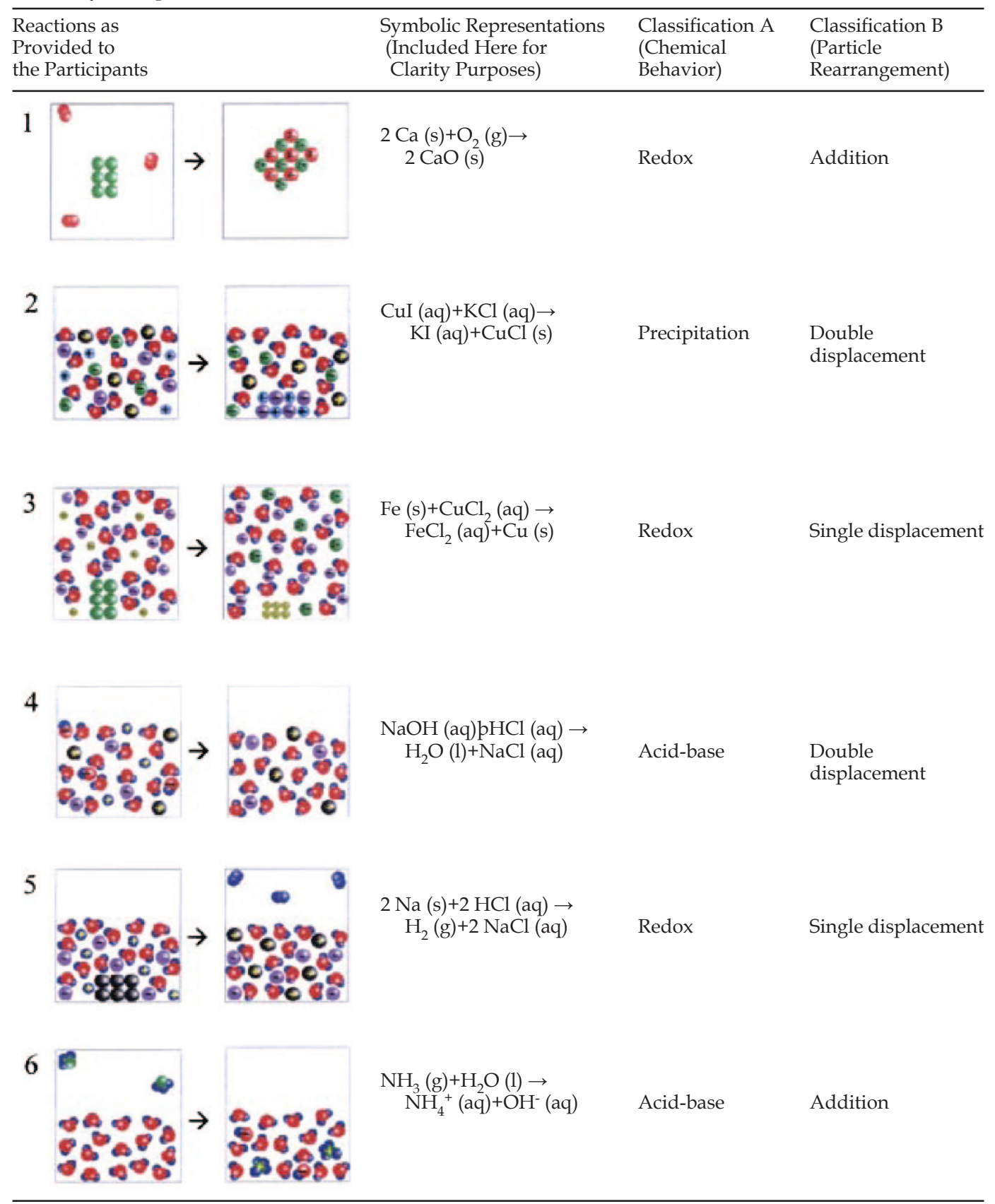

tween types of chemical reactions (classification) or to make sense of the process (sense-making). The codes in Table 4 describe the features used by students to classify the chemical reactions as revealed by the analysis of the transcripts; they do not correspond to the labels assigned by the students to their groupings.

Although interview transcripts were processed using standard methods of qualitative analysis, specialized methods of statistical analysis were applied to verify the existence of perceived patterns 


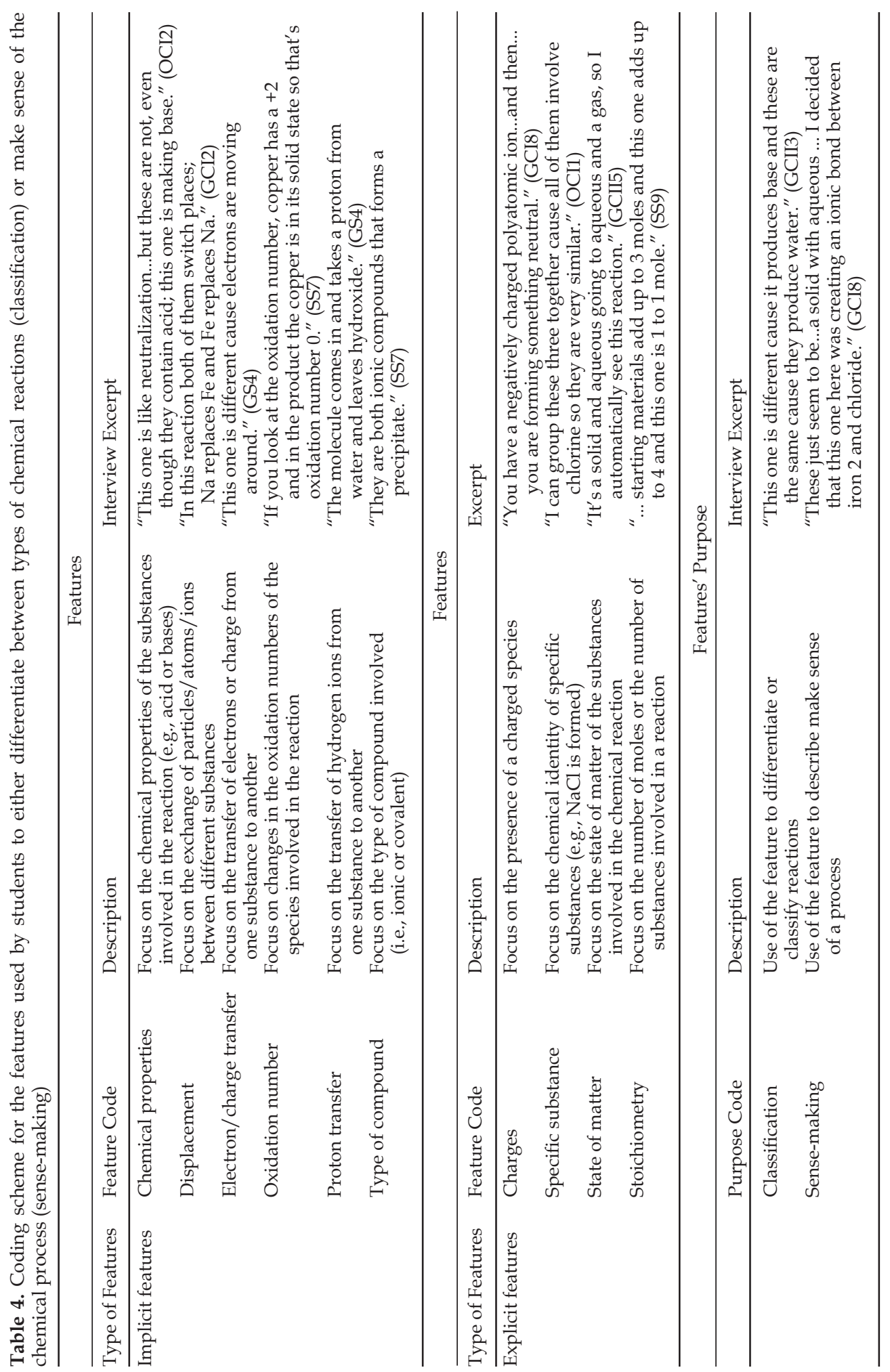


in the data and to further support the validity of our claims. $\alpha=0.05$ was used for all of the statistical results reported in this study. Bonferroni corrections were applied whenever multiple comparisons were made.

\section{Results}

To facilitate the description and discussion of our results, we organized their presentation in five different subsections where we analyze the nature of the classification groups created by participants with different levels of expertise and the types of features used to make the categorization decisions.

\section{Types of Classification Groups}

Analysis of the data revealed wide variability in the types and number of groups of chemical reactions created by the participants with different levels of preparation, particularly among undergraduate students. Table 5 presents representative examples of the types of groupings created by participants during the interviews. The table includes the labels actually assigned by the students, together with the chemical reactions included in each group (see Tables 2 and 3), and the accuracy with which chemical reactions were classified within chemically meaningful groups (based on chemical behavior or particle rearrangement).

Overall, the different categories identified by all of the participants can be organized into two main classes: discipline-based groupings, and non-discipline-based groupings (Figure 1a). The discipline-based groupings include categories that are traditionally used in chemistry, such as acidbase, redox, and precipitation reactions (Classification A in Table 2, based on chemical behavior); or single-displacement, double-displacement, and addition reactions (Classification B in Table 2, based on particle rearrangements). The non-discipline-based groupings correspond to categories that are not traditionally used by expert chemists to classify chemical reactions, and are thus less chemically meaningful. In general, these groupings included categories that refer to two main surface features of the chemical reactions: states of matter of the species involved (e.g., "aqueous reactant" or "solid reaction"); and chemical identity of the reactants or products (e.g., "produce water" or "copper as a solid precipitate").

Analysis of the distribution of discipline-based and non-discipline-based groupings across the different levels of students' preparation in chemistry showed a significant difference, $X^{2}(1, N=207)$ $=24.805, p<0.05$, between undergraduate and graduate students taken as a whole (Figure $1 \mathrm{~b})$. On average, only $36.6 \%$ of the categories created by all of the undergraduate students were disciplinebased categories versus $79.1 \%$ of those created by graduate students. The effect of increasing levels of preparation in chemistry for the different groups at the undergraduate level (GCI, GCII, OCI, and SS) is more difficult to evaluate due to the presence of confounding factors.

Table 5. Types of classification groups created by three participants

\begin{tabular}{|c|c|c|}
\hline SS4 & GCI4 & GCI3 \\
\hline 1. Potassium fluoride (a) & 1. Acid-base $(a, 4) ; \mathbf{1 0 0} \%$ & $\begin{array}{l}\text { 1. Double displacement }(\mathrm{a}, \mathrm{b}, \mathrm{d}, \mathrm{e}) \text {; } \\
\mathbf{1 0 0 \%}\end{array}$ \\
\hline 2. Hydroxide group $(b, 6)$ & $\begin{array}{l}\text { 2. Acid reacts with } \mathrm{H}_{2} \mathrm{O} \text { to form } \\
\text { aqueous ions }(\mathrm{b}, 6)\end{array}$ & $\begin{array}{l}\text { 2. Single displacement } \\
(\mathrm{c}, \mathrm{h}, \mathrm{I}, \mathrm{g}, 6) ; \mathbf{6 0} \%\end{array}$ \\
\hline 3. Gas (c) & 3. Carbonate+acid reaction (c) & 3. Combination (f, $1,2,4) ; 25 \%$ \\
\hline $\begin{array}{l}\text { 4. Forming solid in aqueous } \\
\text { solution }(c, d, f, 2)\end{array}$ & $\begin{array}{l}\text { 4. Double displacement } \\
\text { (d, e); } \mathbf{1 0 0 \%}\end{array}$ & 4. I don't know $(3,5)$ \\
\hline 5. Metal solid (f, $g$ ) & 5. Synthesis (f, 2); $0 \%$ & \\
\hline $\begin{array}{l}\text { 6. I don't know/by themselves } \\
(1,3,4)\end{array}$ & 6. Copper as a solid precipitate $(\mathrm{g})$ & \\
\hline 7. Chloride (i, 5) & $\begin{array}{l}\text { 7. Redox }(\mathrm{h}, 3,5) ; \mathbf{1 0 0} \% \\
\text { 8. Single displacement (i); } \mathbf{1 0 0} \% \\
\text { 9. Solid precipitate (1); } \mathbf{0} \%\end{array}$ & \\
\hline
\end{tabular}

Reactions classified within each group are shown in between parentheses using the same notation as in Tables 2 and 3. Numbers in bold indicate the percentages of the reactions accurately classified within chemically meaningful groups (based on chemical behavior or particle rearrangement). 
a

Types of groups

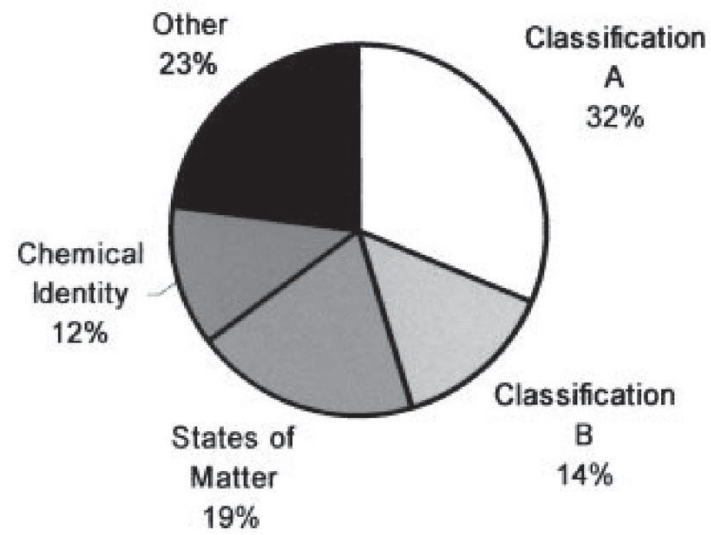

b

Types of groups by level of preparation

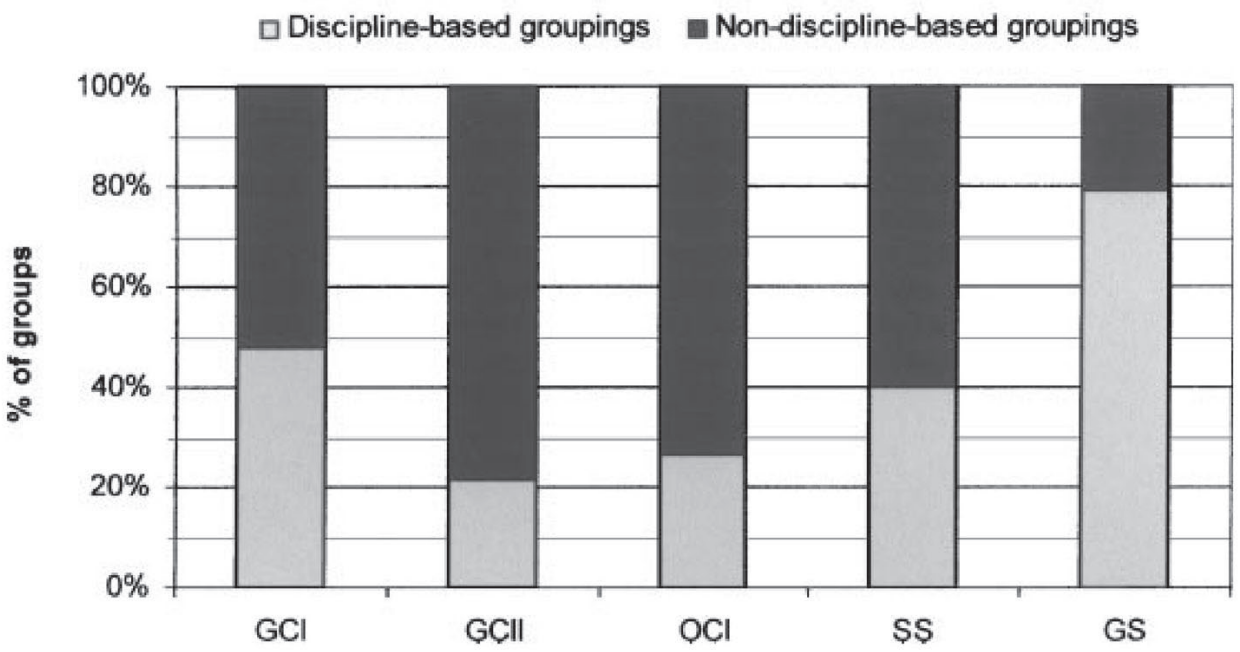

Figure 1. (a) Percentage of different types of groups of chemical reactions created by participants in this study. The fraction labeled "Others" includes non-discipline-based groups with miscellaneous labels (" 1 to 1 ratio," "I don't know"). (b) Percentage of discipline-based and non-discipline-based groups created by students with different levels of preparation.

Participating students from general chemistry I (GCI) created a comparatively high percentage of discipline-based groupings (47.8\%) versus those of other undergraduate students. Most of these groupings were based on the Classification $B$, which distinguishes between the different particle rearrangements induced by a chemical reaction (e.g., double displacement, addition). The discussion of this system of classification is part of the traditional general chemistry curriculum during the first semester, and this knowledge seemed to have influenced the reasoning of a significant proportion of students in this group. Our previous study on classification reasoning patterns also revealed a strong influence of recently acquired knowledge on students' categorization patterns; this "fresh" knowledge is readily available for students to use (Stains \& Talanquer, 2007). However, students in more advanced undergraduate courses did not refer to these types of categories in a substantial way, which may be due to the fact that they had been introduced to other classification systems. 
a

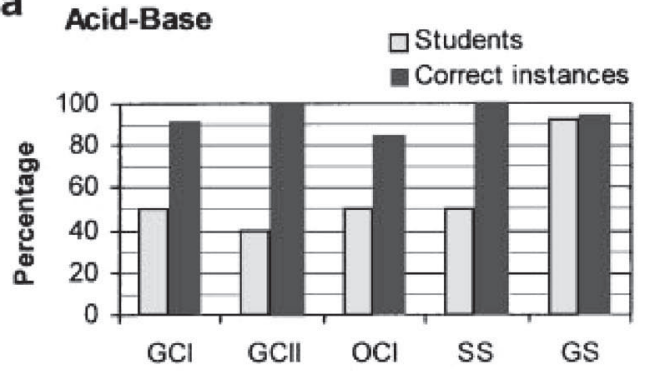

b Redox

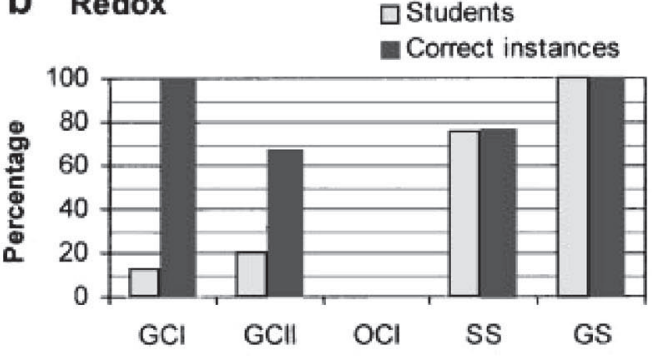

C Precipitation

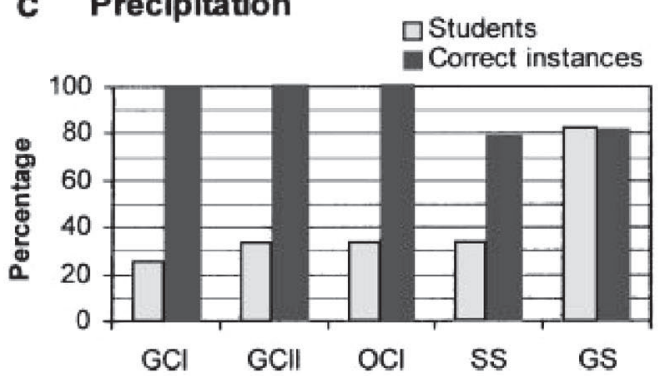

d Single displacement

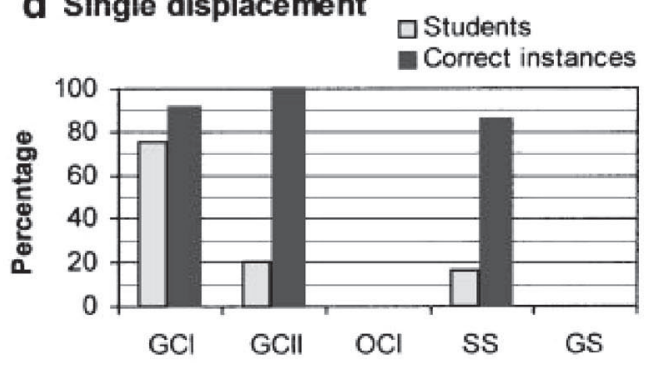

e Double displacement

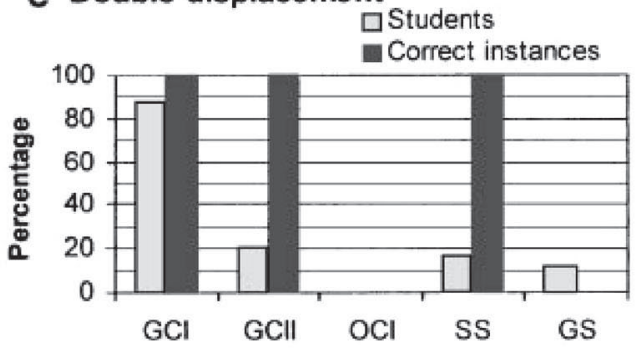

Figure 2. The gray bars show the percentage of students with different levels of preparation who created discipline-based groups according to Classifications A or B in Table 2. The black bars represent the percentage of reactions within each group that were correctly classified.

As shown in Figure 1b, the number of discipline-based groupings created by GCII, OCI, and SS students increased slightly with advanced training. Advanced undergraduate students were more likely to create chemically meaningful groups based on chemical properties or processes, such as acid-base, redox, or precipitation reactions, but still in a surprisingly low proportion (more than $60 \%$ of senior chemistry students created non-discipline-based groupings). A statistical analysis of the data using Spearman's rho $\left(r_{s}\right)$ correlation test reveals that there was a moderate but statistically significant correlation between the level of preparation and the types of classification groups (discipline-based versus non-discipline-based) created when the GCI students were excluded $\left(r_{s}=0.416, p<0.05\right)$.

Our findings indicate that, although few undergraduate students developed discipline-based groupings, they were usually successful in classifying at least some chemical reactions into most of these categories. Figure 2 depicts in different graphs the percentage of students within a given group who chose to create one of the six major discipline-based categories identified by participants in this study (groups from Classifications A and B in Table 2). For example, Figure 2a shows that only $40 \%$ of students in GCII grouped a set of reactions as "acid-base." However, the figure also shows that all of the reactions that these students included within this category were actually acid- 
base reactions. Similarly, less than a third of the general chemistry and organic chemistry students created a "precipitation reaction" category (Figure 2c), but all of the reactions classified in these groups were correctly assigned to the category.

On the other hand, Figure $2 \mathrm{~b}$ and $\mathrm{f}$ suggest that students had more difficulties identifying redox and addition reactions. Redox reaction categories were much less frequently created by GCI, GCII, and OCI students than by senior undergraduate students (SS) and graduate students. GCII students who created redox categories seemed to have difficulties recognizing this type of reaction because more than a third of the reactions included in this category were not redox reactions. Addition reactions were also misinterpreted by many of the students participating in the study. Only half of the reactions that organic chemistry students (OCI) included in the addition reaction category, and none of the reactions that graduate students included in this category were actually addition reactions (Figure 2f). Analysis of the transcripts suggests that the misclassifications of redox reactions and addition reactions were due to misinterpretations of the definitions of fundamental concepts. Several students in our study described a redox reaction as the transformation of a neutral compound into a charged compound, as illustrated by this excerpt (the student is referring to Reaction a in Table 2):

Redox, it's something getting electrons and something losing electrons..., okay, so this one lost an electron cause it went from a neutral molecule to a positive. (SS5)

The overgeneralization of the definition of addition reactions - "two or more substances react to form a single product" - also led more than $25 \%$ of the undergraduate students ( $38 \%$ GCI, $0 \%$ GCII, $50 \% \mathrm{OCI}$, and $17 \%$ SS) to classify the double-displacement reaction $\mathrm{Pb}^{2+}(\mathrm{aq})+2 \mathrm{I}^{-}(\mathrm{aq}) \rightarrow \mathrm{PbI}_{2}(\mathrm{~s})$ as an addition reaction. Many students who misclassified different types of reactions in our study seemed to have a fixed interpretation of certain representational features. For example, an increase in the positive charge of a chemical species was frequently interpreted as due to the loss of electrons, but not as the result of proton transfer; or, the combination of two different species, no matter their nature or the conditions of the reaction, was seen as an addition process. This type of "functional fixedness" has been identified as a characteristic feature of common-sense reasoning in novice chemistry students (Talanquer, 2006).

\section{Levels of Expertise}

The wide variability in both the types of categories created and the accuracy of the classifications made by students within the same subgroup of participants suggested a more complex relationship between level of preparation and level of competence than we expected. To better analyze this relationship, we separated all of the students into three different "levels of expertise" (irrespective of their level of preparation), based on the types of groups they created and their accuracy of the classification of those chemical reactions included in discipline-based groups:

- Novice $(N=18)$ : Less than $25 \%$ of the groups created by these students were discipline-based.

- Intermediate $(N=14)$ : Between $25 \%$ and $75 \%$ of the groups created by these students were discipline-based.

- Advanced $(N=12)$ : At least $75 \%$ of the groups created by these students were discipline-based.

To be counted as a discipline-based group in this analysis, at least $75 \%$ of the reactions included in a group with a discipline-based label had to be accurately classified. For example, student GCI3 in Table 5 was assigned to the intermediate level because only one of the three groups with a discipline-based label had more than $75 \%$ of the reactions correctly categorized.

Figure 3 depicts the distribution of students from each level of preparation among the three levels of expertise just defined. The figure shows that the competence in the classification task of a significant proportion of the undergraduate students was at the novice level, independently of their level of preparation, whereas that of the majority of the graduate students was at the advanced level. However, most of the GCI participants were functioning at an intermediate level, possibly due to the influence of recently acquired knowledge. Figure 3 also indicates that the level of preparation of the undergraduate students was not correlated with level of expertise. However, these results should be taken cautiously due to the small size of the student samples for each of the different levels of preparation. 


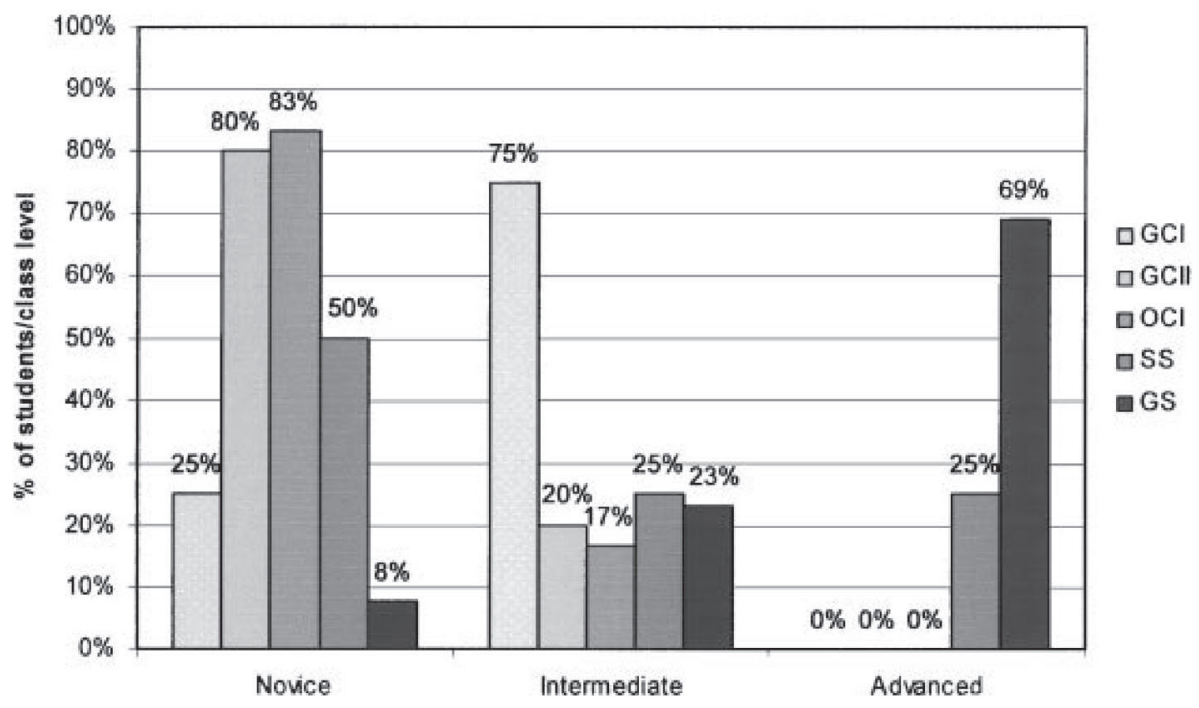

Figure 3. Distribution of students with different levels of preparation at each level of expertise.

The identification of different levels of expertise, independent of level of preparation, is a useful way to analyze the relevant features of the trajectories of expertise in the classification of chemical reactions. For example, Figure 4 shows the proportions of the different types of grouping created by participants with different levels of expertise. Analysis of the figure reveals a transition from categorization based on non-discipline-based groupings at the novice level, to a larger proportion of mixed discipline-based groups of Classifications A and B (Table 2) at the intermediate level, to a dominant use of a Classification A (acid-base, redox, precipitation) at the advanced level. Given our interest in the characterization of the paths toward competence in chemical classification, we used this type of framework to further analyze our data.

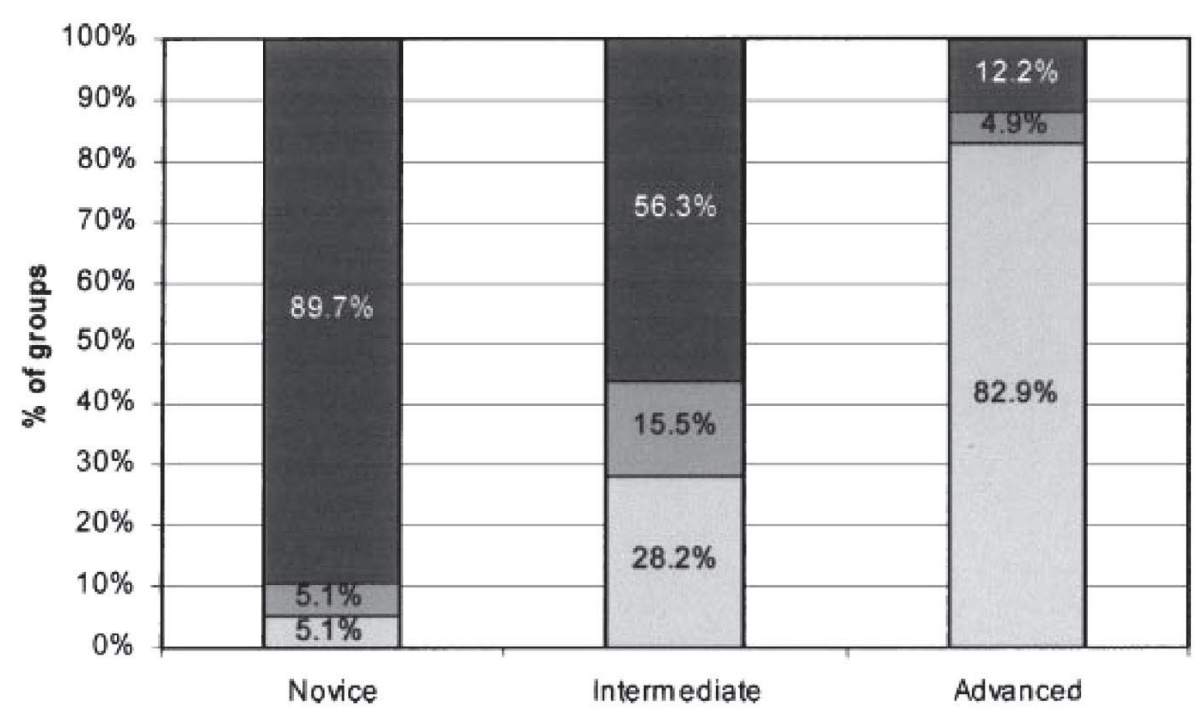

Figure 4. Percentage of types of classification groups created at different levels of expertise.

: non-discipline-based; : Classification B; : Classification A. 


\section{Number and Size of Classification Groups}

The analysis of the categories that students formed during the classification tasks suggests that the level of expertise also affected the number and size of the categories created. Novice students created, on average, 5.39 (standard deviation $[\mathrm{SD}]=1.94)$ groups, compared with $5.07(\mathrm{SD}=1.51)$ groups created by the intermediate students and $3.42(\mathrm{SD}=0.51)$ groups formed by the advanced students, $F(2,41)=6.168, p<0.05$. Bonferroni pairwise post hoc tests show that only the difference between participants at the advanced level and those at the intermediate and novice levels were significant. As the reported SDs reveal, not only the total number but also the range in the number of categories created by different individuals decreased with level of expertise: novice students created between 2 and 11 categories; for intermediate students the range was from 3 to 9, whereas for advanced students it was 3 or 4 . As can be expected from these results, the mean number of chemical reactions within a given category (category size) increased significantly from $2.69(\mathrm{SD}=1.78)$ for the novices to $3.03(\mathrm{SD}=1.46)$ for the intermediates to $4.55(\mathrm{SD}=1.22)$ for the advanced students, $F(2,188)=15.750, p<0.05$. These results are in agreement with those reported by Kozma and Russell (1997) in their work about the effect of expertise on the classification of different representations of chemical phenomena. The findings also support the idea that experts have the ability to perceive larger and more meaningful patterns than novices (Glaser, 1989).

\section{Classification Features}

Analysis of the transcripts reveals that participants considered two types of features while classifying chemical reactions at both the symbolic and microscopic levels: (a) explicit features, which are fully visible elements of a given chemical representation, such as the charge of a particle represented by the symbols +/- or the state of matter of a substance indicated by symbols such as s (for solid) or g (for gas); and (b) implicit features, which are underlying characteristics of the chemical substances or processes not directly expressed or revealed in a representation, such as the oxidation number of an element or the transfer of a proton between different species. In the following subsections, we discuss the specific findings associated with each of these features.

\section{Explicit Features}

Our data reveal that all participants consistently identified the following three explicit features (see also Table 4):

- Particle charge: Students using this feature paid attention to the presence of a charge on a given species and to changes in this quantity during the chemical process.

- States of matter: Students considering this feature highlighted the state of matter of the substances involved in a chemical reaction.

- Presence of specific substances: Students interested in this feature focused on the chemical identity of specific substances (e.g., water is present in the reaction).

Other secondary explicit features included "stoichiometry of the reaction," "characteristics of the products," and "characteristics of the reactants"; these additional features were mostly considered by the novice students.

The level of expertise in chemistry affected the number of explicit features identified during the classification tasks. Although the variety of considered features (total number of explicit plus implicit) increased slightly with the level of expertise, the proportion of explicit features considered by the participants decreased from novice to advanced levels, $F(2,37)=6.000, p<0.05$. This is illustrated in Figure $5 \mathrm{a}$, where we show the average number of different features used by students at each level of expertise and the corresponding proportion of explicit and implicit features. We also analyzed the number of times each participant referred to explicit features during the classification tasks, with the results summarized in Figure $5 \mathrm{~b}$. In general, the frequency of use of explicit features also decreased with the level of expertise, $F(2,37)=3.273, p<0.05$.

Students' identification of explicit features also seemed to be influenced by the type of representations used in the classification task. In general, all participants used a larger variety of features during the classification of chemical reactions represented at the microscopic level $(M=6.52$, 
a

Number of features

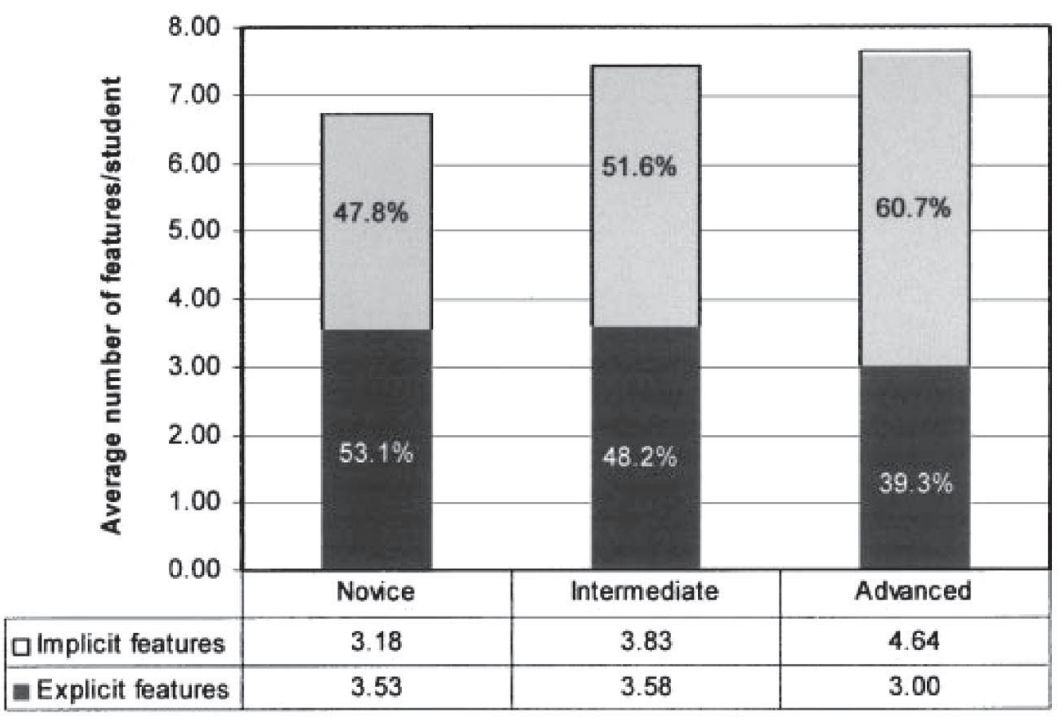

b

Frequency of use

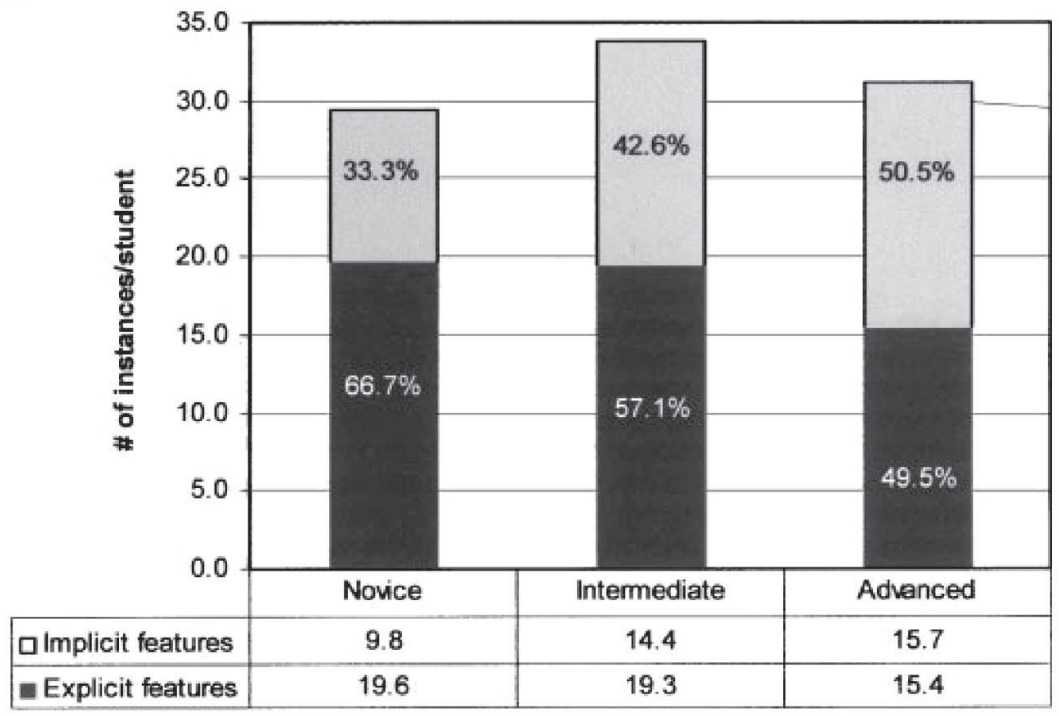

Figure 5. (a) Average number of explicit and implicit features considered per student at different levels of expertise. The proportion of explicit features decreases significantly with increasing expertise, $F(2,37)=6.000$, $p<0.05$, whereas the proportion of implicit features increases, $F(2,37)=5.076, p<0.05$. (b) Frequency of use of explicit and implicit features at different levels of expertise. The frequency of use of explicit features decreases with increasing expertise, $F(2,37)=3.273, p<0.05$, whereas that of implicit features increases, $F(2,37)$ $=5.303, p<0.05$.

$\mathrm{SD}=0.47)$ than at the symbolic level $(M=5.47, \mathrm{SD}=0.46), t(39)=3.852, p<0.05$. This trend can be seen in Figure $6 a$ and $b$, where we depict the average number of features for each type of representation as a function of the level of expertise. The proportion in which explicit features were considered by novice and intermediate students was similar for both types of representations. However, ad- 
$\mathbf{a}$

Symbolic level

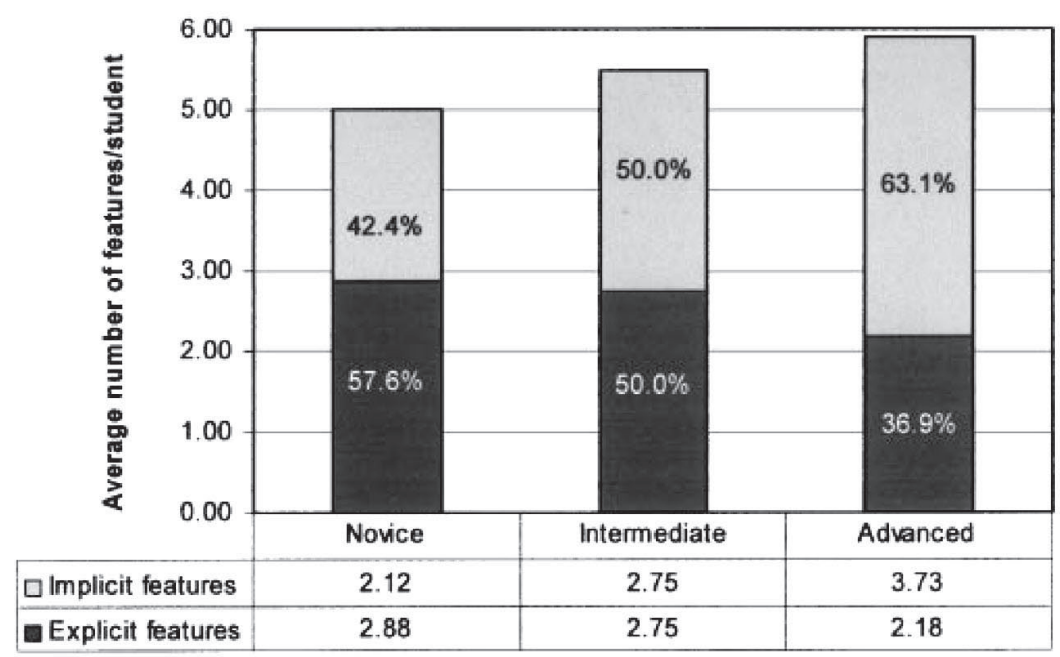

b

Microscopic level

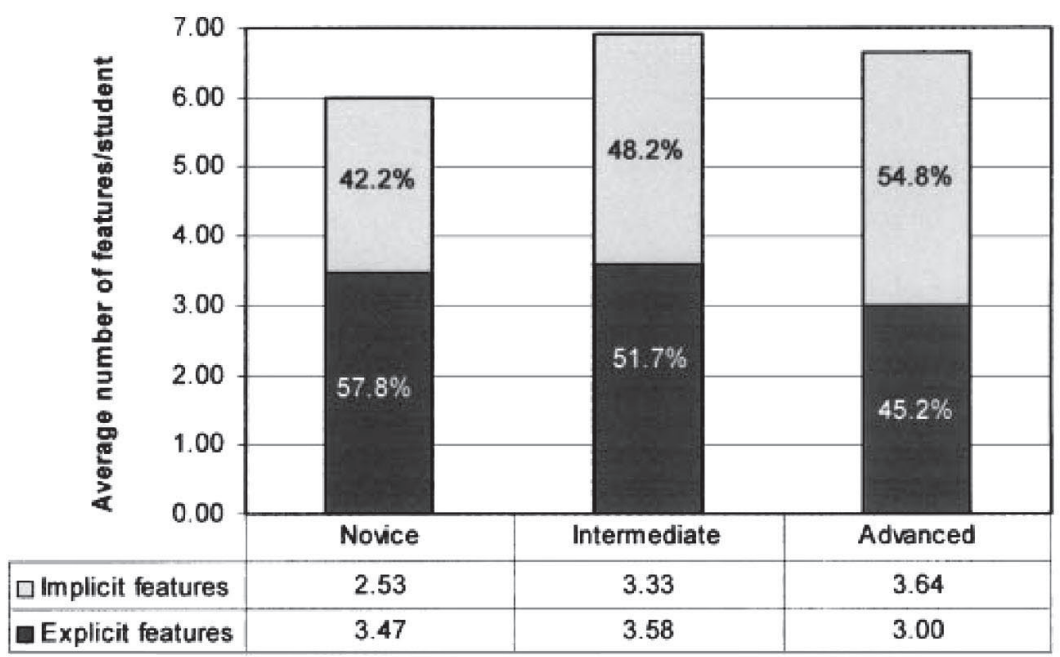

Figure 6. Average number of explicit and implicit features considered per student at different levels of expertise. (a) Reactions represented in symbolic form. The proportion of explicit features decreases significantly with increasing expertise, $F(2,37)=9.150, p<0.05$, whereas the proportion of implicit features increases, $F(2,37)=9.150, p<0.05$. (b) Reactions represented in particulate form. The proportion of explicit features decreases significantly with increasing expertise, $F(2,37)=3.431, p<0.05$, whereas that of implicit features increases, $F(2,37)=3.494, p<0.05$.

vanced students identified a larger proportion of explicit features at the microscopic level than at the symbolic level, $t(10)=-2.549, p<0.05$. The majority of the students interviewed were less familiar with the particulate images of chemical reaction than with their symbolic counterparts and struggled to recognize chemical properties and processes (implicit features) represented at the microscopic level.

The frequency with which explicit features were used during the classification task also varied significantly between the symbolic and microscopic representations. On average, participants re- 
a

Explicit features

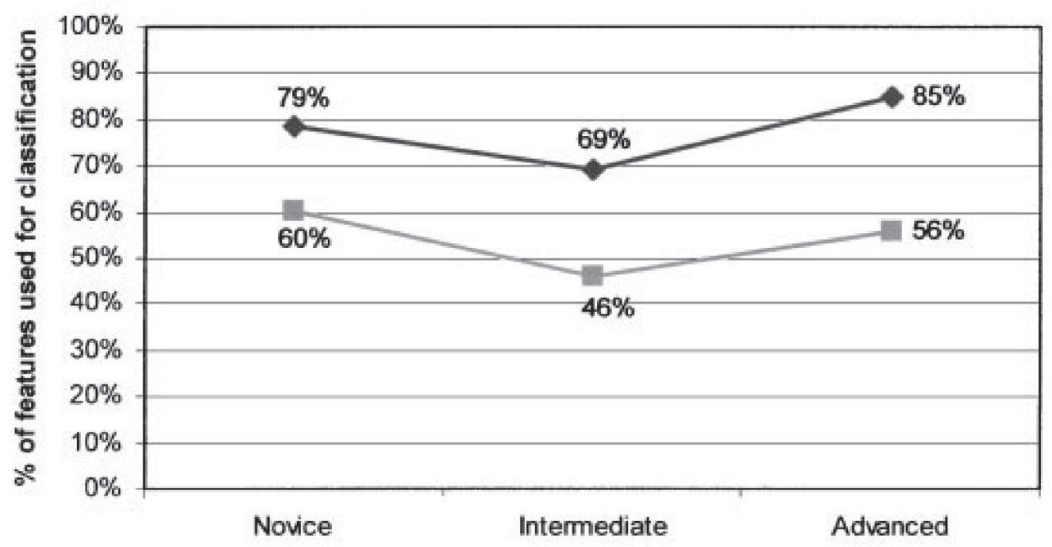

b

Implicit Features

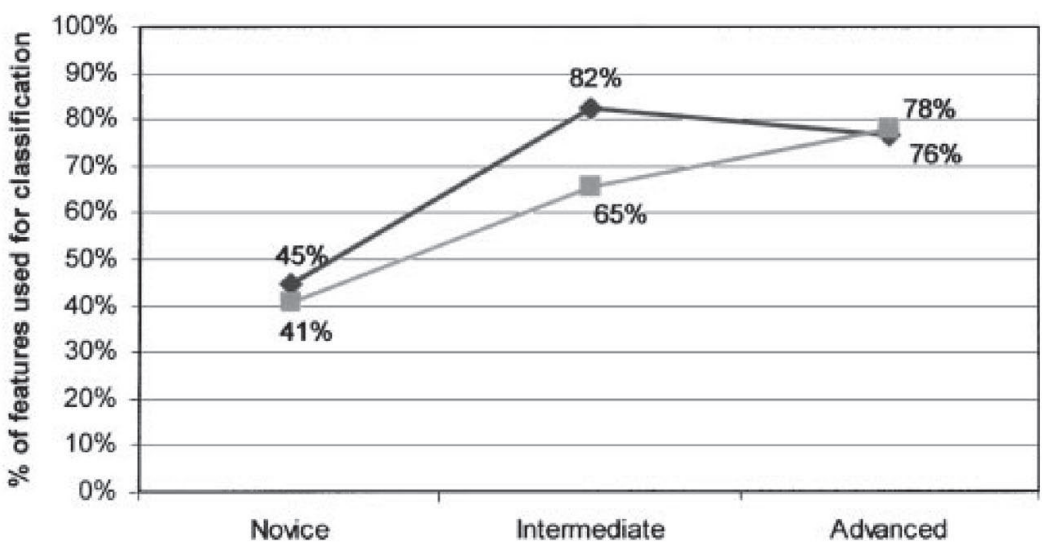

Figure 7. Percentage of different types of features used for classification purposes for reactions represented at the symbolic and microscopic levels. (a) Explicit features. (b) Implicit features. : symbolic; $₫$ : microscopic.

ferred to explicit features $12.4(\mathrm{SD}=3.4)$ times per interview when classifying reactions represented at the microscopic level, with no significant difference among different groups of students. However, for reactions in symbolic form, advanced students used explicit features much less frequently, $4.3(\mathrm{SD}=1.5)$ times per interview, than intermediate, $6.8(\mathrm{SD}=3.5)$, and novice, $7.2(\mathrm{SD}=2.3)$, students, $F(2,37)=4.796, p<0.05$.

Analysis of the transcripts revealed that participants used explicit features for different purposes while working on the classification tasks. In particular, the data suggest that students in our sample used explicit features for two main purposes: categorization and sense-making. When applying an explicit feature for categorization purposes, students would typically use this feature to either differentiate between reactions or as a classification criterion. Students who considered explicit features for sense-making purposes would use these features to identify species involved in the reaction or to describe their properties and the changes induced by the chemical processes.

Figure 7a illustrates the percentage of times that explicit features were considered for categorization purposes by students with different levels of expertise. In general, students at all levels used these types of features primarily for categorization purposes when the chemical reactions were represented in symbolic form. However, as the figure shows, participants used explicit features almost as 
frequently for differentiating among reactions as for making sense of these chemical processes when they were represented in particulate form. Although we did not find a quantitative difference in the application of explicit features among different levels of expertise, analysis of the transcripts revealed major qualitative differences between novice and advanced students. Novice students tended to use explicit features as major classification criteria, building groups around perceived similarities in the states of matter of reactants and products or the presence of specific substances in a chemical reaction. More advanced students used these features as clues to identify discipline-based types of reactions, such as precipitation or acid-base reactions. In addition, although all of the students expressed similar levels of unfamiliarity with the microscopic images of chemical reactions, advanced students were more adept at using the available representational features to build chemical meaning.

\section{Implicit Features}

Participating students also paid attention to a variety of implicit features during the classification tasks (Table 4). Most of the students involved in our study looked at three main implicit features:

- Chemical properties: Students focused on the chemical properties of the substances involved in the reaction (e.g., acid or bases).

- Displacement: Students identified the transfer or exchange of atoms or ions between different species.

- Electron transfer: Students identified the transfer of electrons or charge from one substance to another.

In addition, participants considered other implicit features, such as oxidation number or proton transfer; these types of features were identified mostly by the advanced students.

Expertise in chemistry certainly affected both the variety of implicit features considered during the classification task and the frequency of their use, as shown in Figure $5 \mathrm{a}$ and $\mathrm{b}$. Following an opposite trend to that described for explicit features, the number of implicit features and their frequency increased significantly with the level of expertise. On average, advanced students referred to implicit features over 15 times during a single interview as compared with less than 10 instances in the case of novice students (see Figure $5 b$ ). Compared with other levels of expertise, advanced students used a larger proportion of implicit features than explicit features, $t(10)=6.640, p<0.05$ (Figure 5a), but used both with similar frequency (Figure $5 b$ ). For these participants, chemical reactions represented at the symbolic level seemed to facilitate the identification of implicit features; this effect can be seen by comparing the proportion of implicit features considered by these students when working with symbolic versus microscopic representations (Figure $6 a$ and $b$ ), $t(10)=$ $2.390, p<0.05$. This effect was not significant for the other types of students.

Analysis of the interview transcripts revealed that novice students used implicit features more frequently to describe or make sense of a chemical process rather than to differentiate reactions or build categories (Figure $7 \mathrm{~b}$ ). The application of these types of features for categorization purposes increased with the level of expertise. No significant differences were observed in the way each group of students applied implicit features to the analysis of symbolic and microscopic representations of chemical reactions.

\section{Classification Strategies}

Classification strategies used by the participants were influenced by the level of expertise and the different types of chemical representations used in this study. The effect of each of these factors is analyzed in the following two subsections.

\section{The Role of Expertise}

Comparatively, novice and intermediate students had more difficulties recognizing underlying concepts and used fewer systematic classification strategies than more advanced students. Novices paid attention to a variety of elements in the representation of a chemical process, but were largely focused on surface or explicit features. One common classification strategy among over a third of the novice students ( 7 of 18 students) and a few intermediate students ( 2 of 14 ) was to rely on a specific set of explicit features to recognize members of one or two discipline-based classes of chemi- 
cal reactions (e.g., acid-base or addition). However, if these features were not present or they failed to recognize them, students would tend to switch their attention to a different explicit criterion and create a non-discipline-based grouping:

I was trying to recognize certain characteristics of each molecule and see what I could recall about their reaction with the other one...this one I haven't really seen before and I don't know what to do with it...so I will leave it on the side by itself ...but I don't know what I'm gonna call it. (GCII1Novice)

Gas reacting with a solid, it's not something that I have really been accustomed to too much, so I'll put it off to the side...I will label it "other." (SS1-Intermediate)

Over a quarter of the novice students (5 of 18) relied exclusively on explicit features to classify the chemical reactions and created classification schemes composed of only non-discipline-based categories. Other novice students (4 of 18) correctly identified relevant features characteristic of discipline-based groupings, but they were unable to associate the features with a chemically meaningful class:

It seems like at the beginning that's probably $\mathrm{OH}^{-}$...and it's taking in the $\mathrm{H}^{+}$ions to make more water and leaving the other atoms ....I'm trying to think what it would fitin...maybe...I don't know! ...I guess I think I would put it in here (group liquid to aqueous) just because I'll say it goes from a liquid to some kind of aqueous solution. (OCI4-Novice, talking about Reaction 4 in Table 3)

Analysis of the interviews also revealed that novice students relied on explicit features in order to reduce the cognitive demand of the task. Four of 18 novice students explicitly stated in their interviews that they considered explicit features because of their simplicity, as the following excerpts illustrate:

I think knowing that I'm supposed to be categorizing them it's easy for me to go to the most simple and the most obvious difference which is usually the phases. (OCI1-Novice)

I think the first thing I see is the phases because that's the easiest; you look at it, you can tell what it is, you don't have to think about it...hum...I guess just looking back on it I could have looked at the charges maybe because there are charges among the reactants...but I think the easiest is definitely the phase changes to look at. (OCI4-Novice)

Moreover, 3 of 18 novice students recognized that they should consider implicit features but they decided not to do it because of the high cognitive demand that identifying these types of features requires:

If I had a lot of time to think about it and thought about it really hard, I might regroup them based on oxidation state you know whether that's an oxidation or reduction reaction....but that would take a while to think through so without doing that I would leave them as they are. (SS5-Novice)

In general, novice students tended to use a larger proportion of explicit features than implicit features to build categories, whereas advanced students exhibited a reverse trend (Figure $5 a$ and $b$ ).

Analysis of the transcripts suggests that students' level of analysis was also influenced by recently acquired knowledge or recent experiences in the courses in which they were enrolled. This effect was more pronounced at the lower levels of expertise ( 9 of 18 novices, 6 of 14 intermediates, and 3 of 12 advanced students):

Let's call this a synthesis reaction just because when we did this kind of reaction in my lab that was a synthesis of zinc iodide. (GCI1-Novice)

This one I think I will put it here too because it kind of reminds me of this type of reaction where the addition of one soluble salt, because of its reactivity or its $\mathrm{K}$ value, is more inclined to precipitating with another and so it sort of replaces state with the other. (GCII1-Novice, solubility is a subject covered in this class)

Well, for the first one, I could do it because I was playing with copper oxide this morning...and the picture was easier to think of for me...because I worked in material sciences in industry so we dealt with a lot of metals. (GS1-Advanced) 
In comparison, advanced students in our sample tended to use specific rules that they methodically applied throughout the classification tasks. They considered a well-defined set of features to identify different types of chemical reactions and used them in a systematic way, as the following excerpts illustrate:

\begin{abstract}
...as long as there is two aqueous making a solid it fits in that category (precipitate) and if they are exchanging electrons then it fits into that category (redox). (GS4-Advanced)

I'm basing my decision on...if there is a difference in charge for the element like here, take the iron one for example, we start with iron solid but we go to ferric ions and we go from cuprous to copper solid...so these ones there is an oxidative-reductive reaction happening...over here for the acid-base reaction...everything is aqueous or liquid and all of our charges on each element stay the same...and then for the precipitation reactions, although there is no charge difference, there is a precipitate at the end of the reaction. (GS1-Advanced)
\end{abstract}

\title{
Symbolic Versus Microscopic
}

The classification of symbolic and microscopic representations of chemical reactions triggered different classification strategies among all types of students. Our analysis revealed that all of the participants more frequently used explicit features for sense-making purposes when classifying reactions at the microscopic level than when classifying reactions at the symbolic level (Figure 7a). However, some novice and intermediate students ( 3 of 18 novices and 3 of 14 intermediates) were more inclined to rely on recall and memorization to classify chemical reactions represented at the symbolic level. They were more likely to carefully compare the representations of reactants and products and to identify the changes that had occurred when classifying chemical reactions at the microscopic level. The following excerpts from the interview with one novice student (SS12) are representative of the answers that novice chemists gave to the question, "What do you pay attention to in making your decision?" which was asked during the symbolic and microscopic classification tasks:

I think the first thing I always look for is something that I recognize...like chemicals that I recognize... and I know this is a strong acid, this is a strong base, or this is a strong reducing agent...at this point in chemistry, I'm a senior and I've seen a bunch of chemicals on the board and...professors like to say "everybody knows that this is a strong reducing agent"; so you hear that kind of stuff a lot, so you want to pick that out...and the only time that this happens with these is here (for acid-base)... and everything else I just kind of look at it and say well where would I see these being used. (SS12-Novice, referring to the symbolic representations)

Hum...kind of different actually from...the symbolic ones I look for something that I recognize and all these visual ones they are more intuitive so I'm looking for what's changing ...like what's the big change going on... (SS12-Novice, referring to the microscopic representations)

The different strategies that students used in the symbolic and microscopic classification tasks may be due to their inability to transfer their knowledge from the symbolic level to the microscopic level. For example, some novice and intermediate students ( 3 of 18 novices and 6 of 14 intermediates) were able to identify reactions such as $\mathrm{NaCl}(\mathrm{aq})+\mathrm{AgNO}_{3}(\mathrm{aq}) \rightarrow \mathrm{AgCl}(\mathrm{s})+\mathrm{NaNO}_{3}$ (aq) as either precipitation or double-displacement reactions at the symbolic level, but were unable to do so when the same reaction was represented at the microscopic level (Reaction 2 in Table 3). Some students seemed to think that there were no interactions between substances in the reactions represented in particulate form:

It kind of seems like you shake something up and then it settles down at the bottom as a solid. (OCI4Novice, talking about Reaction 2 in Table 3)

Others did not understand the chemical composition of the reactions:

It just looks like for me the blue and the purple ions are not forming anything so...I think I'm gonna put it in the synthesis reaction just because all the other ions and molecules are just the spectators ions...they are not really doing anything in the reaction. (GCI4-Intermediate, talking about Reaction 2 in Table 3 ) 
As mentioned previously, the lack of familiarity with particulate representations of chemical reactions made it more difficult for participants at all levels of expertise in our study to identify implicit features that could guide their thinking and help them make sense of the nature of the chemical process.

\section{Conclusions and Implications for Science Teaching and Learning}

Chemistry problems often require students to correctly apply classification schemes based on the identification of chemically meaningful features that differentiate one group from another. However, our work in this area indicates that the appropriate identification of these features demands relatively high levels of expertise. Interestingly, the present study also suggests that advanced levels of expertise in chemical classification do not necessarily evolve in a linear and continuous way with academic training. (A significant proportion of undergraduate participants in this study, regardless of their level of preparation in chemistry, exhibited similar reasoning patterns in the classification of chemical reactions.) Recent learning experiences and graduate work in chemistry seem to have a strong impact on students' ability to identify chemically meaningful groups. Given the small size of our samples for each of the different subgroups of participants, further studies are needed to better understand the relationship between level of preparation and level of expertise in classification tasks.

In general, we found that expertise in chemistry influenced the number and types of groups that students created during the classification tasks. Novice students in our study, mostly undergraduates, built classification schemes that contained a wider variety of smaller groups than the classification schemes of advanced students, most of whom were from the graduate level. The analysis of the data also revealed that novice students created significantly fewer discipline-based groupings than their advanced counterparts. Similar results have been reported in a variety of studies focused on expert-novice differences (Chi et al., 1981; Ericsson, 2003; Kozma \& Russell, 1997). Deviations from this pattern seem to be due to the influence of recently acquired knowledge specifically relevant to the classification task at hand. However, our analysis of the classification decisions of students enrolled in more advanced undergraduate courses raises serious doubts about the lasting effects of these learning experiences. As shown in Figures 1 and 3, a large proportion of participating GCI students exhibited an intermediate level of competence during the interviews, whereas most undergraduate students in more advanced courses performed at the novice level. This may indicate that the knowledge and skills required to complete chemical classification tasks are not being learned in meaningful and enduring ways.

All of the participating students referred to explicit and implicit features of the symbolic and microscopic representations of chemical reactions during the associated classification tasks. Advanced students were able to identify and use a significantly larger number of implicit features for sense-making purposes than novice students. The latter students were more inclined to base their classification schemes on surface or explicit features of the different representations, either because they failed to recognize relevant implicit features or because they were trying to reduce the cognitive demand of the task. The identification of surface versus deep approaches to the interpretation of representational features by novice and expert chemists has been reported elsewhere (Kozma \& Russell, 1997; Shane \& Bodner, 2006). The nature of the representations also influenced students' reasoning during the classification process.

The more familiar representations of chemical reactions in symbolic form seemed to trigger the recognition of a larger number of chemically meaningful features, whereas most students struggled in assigning chemical meaning to the microscopic representations of chemical reactions. However, these types of representations forced novice and intermediate students to think more deeply about the nature of the chemical processes by reducing their ability to rely on rote recall. The complexity of and the lack of familiarity with the microscopic representations made most participants analyze more carefully the nature of the chemical processes that were represented.

The comparison of students' performance in the classification of chemical reactions represented at the symbolic and microscopic levels revealed a limitation of our study. In our experimental design, we chose to begin the interview with the set of reactions represented in symbolic form to reduce the effect of lack of familiarity with a given representation on the understanding of the actual classification task. Although this decision was justified by our results, which showed that most 
students had problems interpreting the microscopic representations, it introduced an unexpected effect in the classification strategies of a few students, particularly at the novice level. These students consistently tried to classify the reactions represented in particulate form by comparing them with those represented in symbolic form, looking for a match. This behavior highlighted the need to complete additional studies to explore the effect on our results of reversing the order of completion of the classification task.

The apparent lack of differentiation in the classification skills of undergraduate chemistry students and the significant difference between this group of participants and the graduate students raise questions about the factors that determine the difference. Given the diverse nature of the coursework that the participating graduate students had completed, we suspect that their academic experiences in the classroom were not the major influence. One may speculate that graduate students' involvement in long-term research projects may have created opportunities for them to reflect on the nature and importance of central chemistry concepts, and to better recognize the explanatory and predictive power of the classification systems used by chemists. It is also possible that graduate students represent a group of self-selected students with greater interest and knowledge in chemistry. In addition, their advanced expertise may be the result of their participation in experiences that require them to communicate their knowledge to others. Whether as teaching assistants or tutors, graduate students learn to look at problems and build explanations using canonical ways of thinking in chemistry. Their constant participation in specialized seminars and research group meetings serves to enculturate them in the explanatory practices of the discipline, developing their ability to recognize features and patterns valued in the domain.

Although classification certainly plays a major role in chemical knowledge and ways of thinking, it is also of central importance in other scientific disciplines. Meaningful understanding of the differences between types of objects, interactions, and processes in physical, biological, geological, and planetary systems is a necessary condition for students to build adequate explanations and make predictions. However, our results and analysis indicate that developing this understanding may be a challenging task for most undergraduate students. Traditional teaching practices at the college level assume that students will be able to recognize the explanatory and predictive power of the ways of thinking in the discipline by mere exposure to the accumulated knowledge, without the need to explicitly reflect on the underlying assumptions and ways of knowing in the field. Similarly, we expect students to learn to navigate between the different types or levels of representation used in the various disciplines without targeted training. Unfortunately, these assumptions and expectations are unfounded and run counter to educational research on how people learn (Bransford, 2000).

Our results and analysis highlight the need to create more learning opportunities for college students to reflect on the implicit structure of scientific knowledge and to contrast it with their own knowledge representations. We have an urgent need to reform education at the college level and foster teaching practices that not only encourage reflective and metacognitive thinking, but that also connect central ideas from one course to another (vertical integration). The sharp differences in classification skills between participants in our study suggest that novice students may benefit from opportunities to engage in teaching and research experiences that can help them develop abilities to analyze problems, create models, build explanations, and communicate ideas using the intellectual and practical tools of the trade.

The characteristic knowledge structures or representations that arise as expertise develops in a given field are always partially determined by domain-specific properties (Moss et al., 2006). However, the study of the stages or trajectories of expertise in a given area and the analysis of the approaches used by different types of learners when engaged in solving relevant problems can provide useful information about limitations of the cognitive system that may affect their performance in other disciplines.

\section{References}

Abraham, M.R., Williamson, V.M., \& Westbrook, S.L. (1994). A cross-age study of the understanding of 5 chemistry concepts. Journal of Research in Science Teaching, 31, 147-165.

Al-Kunifed, A., Good, R., \& Wandersee, J. (1993). Investigation of high school chemistry students' concepts of chemical symbol, formula, and equation: Students' prescientific conceptions (Publication no. ED 376020). Retrieved 01/11/2007, from ERIC http://www.eric.ed.gov/ 
Bailenson, J.N., Shum, M.S., Atran, S., Medin, D.L., \& Coley, J.D. (2002). A bird's eyeview: Biological categorization and reasoning within and across cultures. Cognition, 84, 1-53.

Barker, V., \& Millar, R. (2000). Students'reasoning about basic chemical thermodynamics and chemical bonding: What changes occur during a context-based post-16 chemistry course? International Journal of Science Education, 22, 1171-1200.

Barsalou, L.W. (1983). Ad hoc categories. Memory \& Cognition, 11, 211-227.

Benzvi, R., Eylon, B.S., \& Silberstein, J. (1986). Is an atom of copper malleable? Journal of Chemical Education, 63, 64-66.

Birk, J.P., \& Kurtz, M.J. (1999). Effect of experience on retention and elimination of misconceptions about molecular structure and bonding. Journal of Chemical Education, 76, 124-128.

Bransford, J. (2000). How People Learn: Brain, Mind, Experience, and School (expanded edition). Washington, DC: National Academy Press.

Bruner, J.S. (1956). A Study of Thinking. New York: Wiley.

Charmaz, K. (2003). Grounded theory-objectivist and constructivist methods. In: N.K. Denzin \& Y.S. Lincoln (editors), Strategies of Qualitative Inquiry (2nd edition, pp. 249-291). Thousand Oaks, CA: Sage.

Chi, M.T.H., Feltovich, P.J., \& Glaser, R. (1981). Categorization and representation of physics problems by experts and novices. Cognitive Science, 5, 121-152.

Coll, R.K., \& Treagust, D.F. (2001). Learners' mental models of chemical bonding. Research in Science Education, 31, 357-382.

Day, D.V., \& Lord, R.G. (1992). Expertise and problem categorization - the role of expert processing in organizational sense-making. Journal of Management Studies, 29, 35-47.

del Pozo, R.M. (2001). Prospective teachers' ideas about the relationships between concepts describing the composition of matter. International Journal of Science Education, 23, 353-371.

Ericsson, K.A. (2003). The acquisition of expert performance as problem solving. In: J.E. Davidson \& R.J. Sternberg (editors), The Psychology of Problem Solving (pp. 31-83). Cambridge, UK: Cambridge University Press.

Finney, R.M., \& Schwenz, R.W. (2005). Expert and novice categorization of general chemistry problems. Abstracts of Papers of the American Chemical Society, 229, U571-U571.

Gabel, D. (1999). Improving teaching and learning through chemistry education research: A look to the future. Journal of Chemical Education, 76, 548-554.

Glaser, R. (1989). Expertise and learning: How do we think about instructional processes now that we have discovered knowledge structures? In: D. Klahr \& K. Kotovsky (editors), Complex Information Processing: The Impact of Herbert A. Simon (pp. 269-282). Hillsdale, NJ: Erlbaum.

Hayes, B.K., Foster, K., \& Gadd, N. (2003). Prior knowledge and subtyping effects in children's category learning. Cognition, 88, 171-199.

Hmelo, C.E. (1998). Problem-based learning: Effects on the early acquisition of cognitive skill in medicine. Journal of the Learning Sciences, 7, 173-208.

Johnson, K.E. (2001). Impact of varying levels of expertise on decisions of category typicality. Memory $\mathcal{E}$ Cognition, 29, 1,036-1,050.

Johnstone, A.H. (1993). The development of chemistry teaching-a changing response to changing demand. Journal of Chemical Education, 70, 701-705.

Kozma, R.B., \& Russell, J. (1997). Multimedia and understanding: Expert and novice responses to different representations of chemical phenomena. Journal of Research in Science Teaching, 34, 949- 968.

Lajoie, S.P. (2003). Transition and trajectories for studies of expertise. Educational Researcher, 32, 21-25.

Larkin, J. (1983). The role of problem representation in physics. In: D. Gentner \& A.L. Stevens (editors), Mental Models (pp. 75-98). Hillsdale, NJ: Erlbaum.

Margolis, E., \& Laurence, S. (1999) Concepts: Core Readings. Cambridge, MA: MIT Press.

Medin, D.L., Lynch, E.B., Coley, J.D., \& Atran, S. (1997). Categorization and reasoning among tree experts: Do all roads lead to Rome? Cognitive Psychology, 32, 49-96.

Moss, J., Kotovsky, K., \& Cagan, J. (2006). The role of functionality in the mental representations of engineering students: Some differences in the early stages of expertise. Cognitive Science, 30, 65-93. Murphy, G.L. (2002). The Big Book of Concepts. Cambridge, MA: MIT Press. 
Murphy, G.L., \& Medin, D.L. (1985). The role of theories in conceptual coherence. Psychological Review, 92, 289-316.

Nakhleh, M.B., \& Samarapungavan, A. (1999). Elementary school children's beliefs about matter. Journal of Research in Science Teaching, 36, 777-805.

Palmeri, T.J., \& Blalock, C. (2000). The role of background knowledge in speeded perceptual categorization. Cognition, 77, B45-B57.

Papageorgiou, G., \& Sakka, D. (2000). Primary school teachers' views on fundamental chemical concepts. Chemistry Education: Research and Practice in Europe, 1, 237-247.

Rosch, E., Mervis, C.B., Gray, W.D., Johnson, D.M., \& Boyesbraem, P. (1976). Basic objects in natural categories. Cognitive Psychology, 8, 382-439.

Rouder, J.N., \& Ratcliff, R. (2006). Comparing exemplar-and rule-based theories of categorization. Current Directions in Psychological Science, 15, 9-13.

Sanger, M.J. (2000). Using particulate drawings to determine and improve students' conceptions of pure substances and mixtures. Journal of Chemical Education, 77, 762-766.

Schummer, J. (1998). The chemical core of chemistry 1: A conceptual approach. Hyle, 4, 129-162.

Shane, J.W., \& Bodner, G.M. (2006). General chemistry students' understanding of structure-function relationships. Chemical Educator, 11, 130-137.

Stains, M., \& Talanquer, V. (2007). Classification of chemical substances using particulate representations of matter: An analysis of student thinking. International Journal of Science Education, 29, 643-661.

Talanquer, V. (2006). Commonsense chemistry: A model for understanding students' alternative conceptions. Journal of Chemical Education, 83, 811-816.

Tanaka, J.W., \& Taylor, M. (1991). Object categories and expertise - is the basic level in the eye of the beholder. Cognitive Psychology, 23, 457-482.

Thagard, P., \& Toombs, E. (2005). Atoms, categorization and conceptual change. In: C. Lefebvre (editor), Handbook of Categorization in Cognitive Science (pp. 243-254). Amsterdam: Elsevier.

Wu, H.K., \& Shah, P. (2004). Exploring visuospatial thinking in chemistry learning. Science Education, 88, 465-492. 